\title{
Equine vitiligo-like depigmentation in grey horses is related to genes involved in immune response and tumor metastasis
}

\author{
Thomas Druml ${ }^{*}$, Gottfried Brem ${ }^{1}$, Brandon Velie ${ }^{2}$, Gabriella Lindgren ${ }^{3,4}$, Michaela Horna ${ }^{5}$, Anne Ricard ${ }^{6,7}$ and \\ Gertrud Grilz-Seger ${ }^{1}$
}

\begin{abstract}
Background: In horses, the autoimmune disease vitiligo is characterized by the loss of melanocytes and results in patchy depigmentation of the skin around the eyes, muzzle and the perianal region. Vitiligo-like depigmentation occurs predominantly in horses displaying the grey coat colour and is observed at a prevalence level of $26.0-67.0 \%$ in grey horses compared with only $0.8-3.5 \%$ in non-grey horses. While the polygenetic background of this complex disease is well documented in humans, the underlying candidate genes for this skin disorder in horses remain unknown. In this study we aim to perform a genome-wide association study (GWAS) for identifying putative candidate loci for vitiligo-like depigmentation in horses.
\end{abstract}

Methods: In the current study, we performed a GWAS analysis using high-density $670 \mathrm{k}$ single nucleotide polymorphism (SNP) data from 152 Lipizzan and 104 Noriker horses, which were phenotyped for vitiligo-like depigmentation by visual inspection. After quality control 376,219 SNPs remained for analyses, the genome-wide Bonferroni corrected significance level was $p<1.33$ e-7.

Results: We identified seven candidate genes on four chromosomes (ECA1, ECA13, ECA17, ECA20) putatively involved in vitiligo pathogenesis in grey horses. The highlighted genes PHF11, SETDB2, CARHSP1 and LITAFD, are associated with the innate immune system, while the genes RCBTB1, LITAFD, NUBPL, PTP4A1, play a role in tumor suppression and metastasis. The antagonistic pathogenesis of vitiligo in relation to cancer specific enhanced cell motility and/ or metastasis on typical melanoma predilection sites underlines a plausible involvement of RCBTB1, LITAFD, NUBPL, and PTP4A1.

Conclusions: The proposed candidate genes for equine vitiligo-like depigmentation, indicate an antagonistic relation between vitiligo and tumor metastasis in a horse population with higher incidence of melanoma. Further replication and expression studies should lead to a better understanding of this skin disorder in horses.

Keywords: Vitiligo, Lipizzan horse, GWAS, Melanoma, Tumor metastasis

\section{Background}

Vitiligo-like depigmentation in horses occurs predominantly in animals of grey coat colour and is characterized by progressive patchy depigmentation of the skin around the eyes, muzzle and the perianal region. This skin disorder is caused by the loss of melanocytes that produce epidermal pigment. In humans, vitiligo affects skin areas mainly in the face, hands, feet, and genitals and is observed in $0.5-2.0 \%$ of the population 
[1]. The pathogenesis of human vitiligo is described as an interaction between intrinsic melanocyte defects, autoimmune mechanisms, and environmental and genetic factors [2]. Melanocytes from normal pigmented skin areas of vitiligo patients differ from those of healthy patients as they grow less efficient and exhibit structural defects $[1,3]$. In addition to intrinsic abnormalities, it has also been shown that exogeneous oxidative stress factors can initiate a higher level of melanocyte destruction in vitiligo affected individuals [4]. The autoimmune hypothesis, which represents the leading model to explain the etiopathogenesis of vitiligo, rests upon studies that documented higher levels of melanocyte specific antibodies capable of destroying cultured melanocytes in vitro $[5,6]$. Moreover, vitiligo affected skin is characterized by elevated infiltration of killer cells and inflammatory dendritic cells and the higher level of cytotoxic $\mathrm{CD} 8^{+} \mathrm{T}$ lymphocytes in blood and skin of vitiligo patients [7-9]. Throughout the last few decades, genetic factors associated with vitiligo and vitiligo-like skin disorders have been studied by the use of high throughput technologies like high-density SNP (single nucleotide polymorphism) genotyping and NGS (next generation sequencing) related methods $[2,10,11]$. In humans, more than 40 susceptible loci have been verified by means of genome-wide association studies (GWAS), further supporting established pathways involved in the pathogenesis of this skin disease. To date, the identified risk loci can be assigned to five groups: (a) human leukocyte antigen genes (HLA/ MHC region); (b) immunoregulatory genes; (c) melanocyte related genes; (d) apoptotic and cytotoxic genes and (e) loci with unknown functions for vitiligo [2]. However, a 'convergence theory', which summarizes the combination of all known aetiologic factors that impact melanocyte viability in epidermal tissue has recently been proposed [12].

Although vitiligo has been the object of intensive genomic scientific research in humans $[2,10,11,13]$ the genetic background of this autoimmune disease in horses remains unknown. Currently, phenotypic animal models of vitiligo-like depigmentation have been described in horses [14], dogs [14], cats [14], pigs [1], chickens [1], and mice [1]. In horses, clinical studies were presented for twelve Gelderlands, nine Thoroughbreds, four Arabians, four Belgians, one Oldenburg, one Mecklenburg, and one Quarter Horse [15-20]. Further reports of vitiligo-like phenotypes were published for Arabian horses (Arabian fading syndrome) [21, 22] Pura Raza Espanola - P.R.E., Kladrubian, and Lipizzan horses. These horse breeds are characterized by medium to high allele frequencies of the grey coat colour associated STX17 mutation, which is causative for progressive greying and involved in vesicle transport [23-26].
Population genetic studies providing heritability and genetic correlation estimates for vitiligo-like depigmentation and melanoma in grey horses have also been performed by Curik et al. [24], Hofmanova et al. [25], and Sanchez-Guerrero et al. [26]. In a total population of 11,436 P.R.E. horses (prevalence of vitiligo-like depigmentation ranged from $2.8-20.5 \%$, whereas in 5.044 grey P.R.E. horses higher values from $3.6-49.8 \%$ were reported [26]. For 376 grey Kladrubian horses Hofmanova et al. [25] documented a prevalence of 26.0 to $67.0 \%$, and in Lipizzans vitiligo-like phenotypes have been reported to occur in $39.9-50.0 \%$ of horses [24, 27]. In all studies an increase of vitiligo-like depigmentation with age was shown, with the largest increase observed between 5 and 7 years. Heritability estimates for this depigmentation phenotype ranged from 0.09 to 0.64 . The higher estimates were calculated for samples with higher frequencies of the greying associated G-allele on the STX17 locus $\left(h^{2}\right.$ of 0.64 in Lipizzans [24], $h^{2}$ of 0.62 in grey P.R.E [26]., $\mathrm{h}^{2}$ of 0.35 in grey Kladrubian horses [25]). Genetic correlations between vitiligo-like depigmentation and melanoma were reported as between -0.19 and 0.28 , with the level of progressive greying yielding higher genetic correlations (0.48 to 0.67 ) to vitiligo-like depigmentation. Curik et al. [24] assigned a partial heritability to the STX17 locus of 0.23, which reduced the polygenetic heritability from 0.64 to 0.41 . These results clearly demonstrate that vitiligo-like depigmentation in horses occurs at higher levels in horse breeds selected for grey coat colour and that it is characterized by moderate to medium heritability thereby indicating the presence of environmental effects and/or polygenetic background.

Despite multiple investigations into vitiligo in horses, genomic studies on vitiligo-like depigmentation have yet to be conducted. As such, in this study we performed a genome-wide association study to identify susceptibility genes or loci associated with vitiligo-like depigmentation in a cohort of Lipizzan horses selected for grey coat colour.

\section{Results \\ Prevalence and effects of coat colour loci on vitiligo-like depigmentation grade}

In the sample cohort of 152 phenotyped Lipizzan horses the vitiligo prevalence was $21.7 \%$ (33 horses from 152; Table 1). Phenotype distribution by age classes are presented in Fig. 1. From Table 1 and Fig. 1 a slight shift of higher vitiligo-like depigmentation towards higher individual age of horses can be observed, where 12 horses with grade 3 were on average 17.5 years old and 119 horses with grade 0 had an average age of 14.6 years ( 4 horses younger than 7 years were solid coloured). 
Table 1 Observations, percentage, mean age and standard deviation of mean age (s.d.) for vitiligo-like depigmentation grade in 152 Lipizzan horses

\begin{tabular}{lllll}
\hline Vitiligo grade & Observations & Percentage & Mean age & s.d. of age \\
\hline 0 & 119 & 78.29 & 14.56 & 7.38 \\
0.5 & 12 & 7.89 & 16.08 & 5.57 \\
1 & 4 & 2.63 & 16.00 & 6.73 \\
2 & 5 & 3.29 & 17.80 & 8.90 \\
3 & 12 & 7.89 & 17.50 & 4.64 \\
& 152 & 100 & 15.06 & 7.05 \\
\hline
\end{tabular}

In Table 2 the genotype frequencies for the coat colour loci ASIP, MC1R and STX17 within the sample cohort are given. From the coat colour genotype distribution only one chestnut ( $M C 1 R$ genotype $e / e$ ) was detected. Within the other Lipizzans the $M C 1 R$ locus was nearly fixed for the dominant $E$-allele, which resulted in an allele frequency of 0.97. The allele frequency for the grey associated $G$-allele on $S T X 17$ was 0.83 and 0.59 for the $A$-allele on ASIP locus. The sample included 12 Lipizzan horses of non-grey coat colour, which did not exhibit vitiligo-like depigmentation. The generalized linear model (GLM) including the fixed effects ASIP, MC1R and STX17 genotype and age class, was able to explain $13.0 \%$ of observed variation in the dataset, whereas only the effect age class revealed a significant $p$-value of 0.046 . The coat colour genotypes of MC1R, ASIP and STX17 did not show an effect on vitiligo-like depigmentation in this sample of Lipizzan horses.

\section{Genome-wide association analysis (GWAS)}

The SNP-based heritability estimate for vitiligo-like depigmentation grade reached a level of 0.31 (s.d. 0.13). Genome-wide association analyses resulted in the detection of 17 genome-wide significant SNPs on 10 chromosomes (ECA1, 5, 6, 7, 9, 13, 15, 17, 20 and 23) (Fig. 2). Five SNPs were located within following genes: NUBPL (nucleotide binding protein like) on ECA1 (AX104837465; $p=1.14 \mathrm{e}-07$; intronic variant), KCTD5 (potassium channel tetramerization domain containing 5) on ECA13 (AX-104387837; $p=1.88 \mathrm{e}-08$; intronic variant), PHF11 (PHD finger protein 11) on ECA17 (AX104594172; $p=9.97 \mathrm{e}-08$; intronic variant), CARMIL1 (capping protein regulator and myosin 1 linker 1) (AX103235989; $p=6.38 \mathrm{e}-08$ ) and PTP4A1 (protein tyrosine phosphatase 4A1) (AX-103697053; $p=1.06 \mathrm{e}-07$; intronic variant) on ECA20.

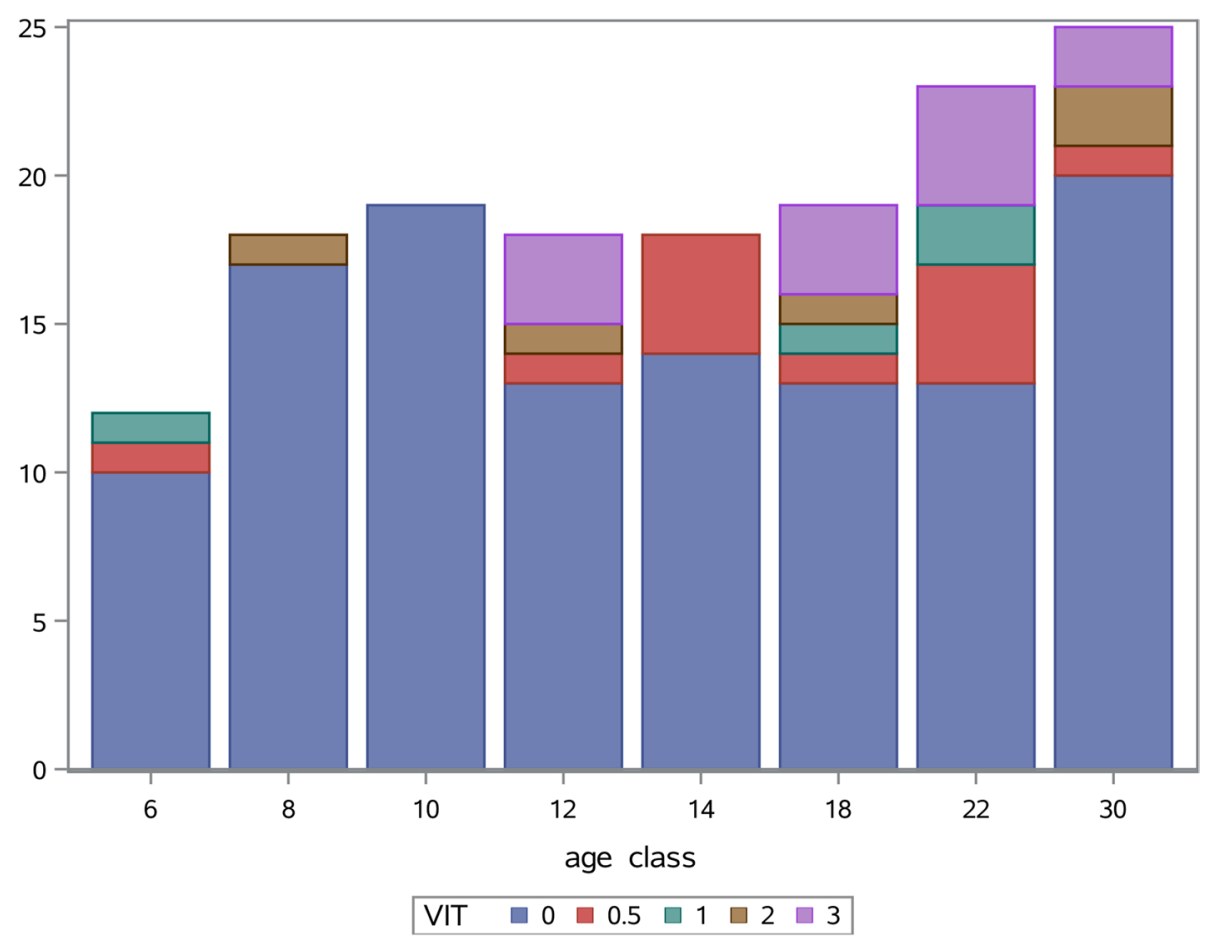

Fig. 1 Distribution of 152 Lipizzan horses according to vitiligo-like depigmentation grade VIT (blue = grade 0 ; red = grade 0.5 ; green = grade 1; brown $=$ grade 2 ; purple $=$ grade 3 ) by age classes (class $6=4$ to 6 years; class $8=7$ to 8 years; class $10=9$ to 10 years; class $12=11$ to 12 years; class $14=13$ to 14 years; class $18=15$ to 18 years; class $22=19$ to 22 years; class $30=23$ to 34 years) 
Table 2 Genotype distribution of ASIP, MC1R and STX17 in 152 Lipizzan horses by vitiligo-like depigmentation grade

\begin{tabular}{|c|c|c|c|c|c|c|c|c|c|c|}
\hline \multirow{2}{*}{$\begin{array}{l}\text { Vitiligo } \\
\text { grade }\end{array}$} & \multicolumn{3}{|c|}{$A S I P$} & \multicolumn{3}{|c|}{ MC1R } & \multicolumn{3}{|c|}{ STX17 } & \multirow[b]{2}{*}{ Sum } \\
\hline & $A / A$ & $A / a$ & $a / a$ & $E / E$ & $E / e$ & $e / e$ & $g / g$ & $G / g$ & $G / G$ & \\
\hline 0 & 34 & 64 & 21 & 112 & 6 & 1 & 12 & 30 & 77 & 119 \\
\hline 0.5 & 2 & 6 & 4 & 12 & 0 & 0 & 0 & 0 & 12 & 12 \\
\hline 1 & 2 & 2 & 0 & 3 & 1 & 0 & 0 & 0 & 4 & 4 \\
\hline 2 & 3 & 2 & 0 & 4 & 1 & 0 & 0 & 1 & 4 & 5 \\
\hline 3 & 6 & 6 & 0 & 12 & 0 & 0 & 0 & 4 & 8 & 12 \\
\hline Sum & 47 & 80 & 25 & 143 & 8 & 1 & 12 & 35 & 105 & 152 \\
\hline
\end{tabular}

From the significant SNPs, 8 SNPS were located in a window frame of $+/-25 \mathrm{~kb}$ containing one or two genes. These annotated genes were: OR6N1 (olfactory receptor $6 \mathrm{~N} 1$ ), OR6N2 (olfactory receptor $6 \mathrm{~N} 2$ ) on ECA5, CLEC4D (C-type lectin domain family 4 member D) on ECA6, HNF4G (hepatocyte nuclear factor 4 gamma) on ECA9, LITAFD (LITAF domain containing), CARHSP1 (calcium regulated heat stable protein 1), OR2C1 (olfactory receptor family 2 subfamily $\mathrm{C}$ member 1 ), PDPK1 (3-phosphoinositide dependent protein kinase 1) and AMDHD2 (amidohydrolase domain containing 2) on ECA13, and RCBTB1 (RCC1 and BTB domain containing protein 1) and SETDB2 (SET domain bifurcated histone lysine methyltransferase 2) on ECA17. Lastly, we identified 11 SNPs on eight chromosomes with annotated genes. Exact location, GWAS $p$-values, and gene annotation of the in total 17 significantly associated SNPs are given in Table 3.

We further replicated the genotypes of the retained eleven SNPs with gene annotation within 1490 samples of the breeds Anglo-Arabian, Shagya-Arabian, Purebred Arabian, Partbred Arabian, Exmoor Pony, Selle Francais, Lipizzan, French Trotter, and Noriker. The sample of Lipizzan horses comprised 377 animals including Lipizzans from Slovak, Croatian and Hungarian stud farms and the samples of 174 Noriker horses contained animals of leopard spotting coat colour besides animals of the three basic colours bay, black and chestnut.

For the Anglo-Arabian, Purebred Arabian and Partbred Arabian samples we assumed according to breeding program definition a potential prevalence of $30-40 \%$ animals of grey coat colour. In Shagy Arabians $53 \%$ of animals were grey and within Noriker and Exmoor Pony grey coat colour does not segregate. In the breeds Selle Francais and French Trotter grey coat colour may occur at a low to moderate level (5-20\%).

Out of the eleven SNPs, six loci (AX-104234663 (ECA5:35,033,603), AX-104673609 (ECA6:36,234,703), AX-104336590 (ECA9:11,650,147), AX-104387837 (ECA13:41,408,155), AX-104370576 (ECA13:41,503,474), AX-103235989 (ECA20:24,186,084)) did not show a meaningful genotype distribution, as higher proportion of genotypes associated with vitiligo-like depigmentation occurred at moderate level also in non-grey samples or samples where vitiligo-like phenotypes were not observed (Table 4).

From the remaining five SNPs, the locus AX-104837465 (ECA1: 170,926,834), located within NUBPL, exhibited a nearly perfect association across breeds (46 heterozygous and 4 homozygous Lipizzans for the associated allele; 2

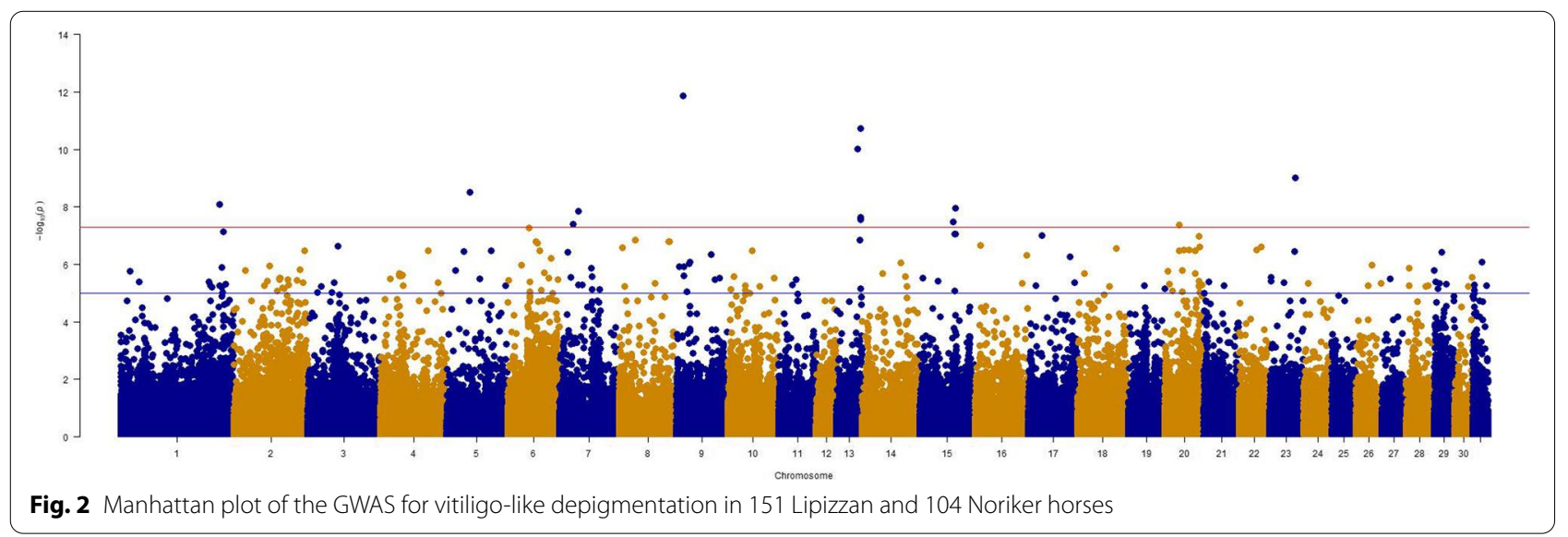


Table 3 Significantly with vitiligo-like depigmentation associated SNPs including information on their position, $p$-values and annotated genes (genic $=$ SNP located within gene; intergenic $=$ SNP located in a $+/-25 \mathrm{~kb}$ window next to the gene)

\begin{tabular}{|c|c|c|c|c|c|c|c|c|c|}
\hline Chr & SNP & $\begin{array}{l}\text { rs SNP } \\
\text { number }\end{array}$ & $p$-value & $\begin{array}{l}\text { Position } \\
\text { EquCab3 }\end{array}$ & genic & gene region & $\begin{array}{l}\text { genic SNP } \\
\text { variant }\end{array}$ & $\begin{array}{l}\text { intergenic } \\
-25 \mathrm{~kb}\end{array}$ & intergenic $+25 \mathrm{~kb}$ \\
\hline 9 & AX-104336590 & rs68729604 & $1,18 \mathrm{E}-12$ & $11,650,147$ & & & & & HNF4G \\
\hline 13 & AX-104939678 & rs1143810305 & $3,86 \mathrm{E}-11$ & $40,644,649$ & & & & & OR2C1 \\
\hline 13 & AX-104150856 & rs1145360759 & $1,88 \mathrm{E}-10$ & $36,289,780$ & & & & LITAFD & CARHSP1 \\
\hline 23 & AX-104329626 & rs1148154226 & 1,14E-09 & $42,288,906$ & & & & & \\
\hline 5 & AX-104234663 & rs1138936192 & 3,13E-09 & $35,033,603$ & & & & OR6N2 & OR6N1 \\
\hline 7 & AX-104687221 & rs1150319641 & $1,03 \mathrm{E}-08$ & $32,228,883$ & & & & & \\
\hline 1 & AX-103991294 & rs1138560853 & $1,03 \mathrm{E}-08$ & $164,725,011$ & & & & & \\
\hline 15 & AX-103257076 & rs1151004238 & $1,27 \mathrm{E}-08$ & $59,455,614$ & & & & & \\
\hline 13 & AX-104370576 & rs1141793424 & $1,80 \mathrm{E}-08$ & $41,503,474$ & & & & PDPK1 & AMDHD2 \\
\hline 13 & AX-104387837 & rs68927375 & $1,88 \mathrm{E}-08$ & $41,408,155$ & KCTD5 & $\begin{array}{l}13: 41387118- \\
41,414,697\end{array}$ & intronic (protein & coding) & PDPK1 \\
\hline 7 & AX-103298246 & rs1149149950 & $4,21 \mathrm{E}-08$ & $23,815,408$ & & & & & \\
\hline 15 & AX-104882695 & rs69007837 & $6,30 \mathrm{E}-08$ & $56,537,568$ & & & & & \\
\hline 20 & AX-103235989 & rs1147491448 & $6,38 \mathrm{E}-08$ & $24,186,084$ & CARMIL1 & $\begin{array}{l}20: 23987962- \\
24,299,401\end{array}$ & intronic (protein & coding) & \\
\hline 17 & AX-104594172 & rs1145363295 & 9,97E-08 & $21,505,125$ & PHF11 & $\begin{array}{l}17: 21489896- \\
21,518,337\end{array}$ & $\begin{array}{l}\text { intronic (exon } \\
5 \text { ) }\end{array}$ & RCBTB1 & SETDB2 \\
\hline 20 & AX-103697053 & rs1148983319 & $1,06 \mathrm{E}-07$ & $57,714,448$ & PTP4A1 & $\begin{array}{l}20: 57711442- \\
57,718,044\end{array}$ & intron 3 & & \\
\hline 6 & AX-104673609 & rs1143140285 & $1,09 \mathrm{E}-07$ & $36,234,703$ & & & & CLEC4D & \\
\hline 1 & AX-104837465 & rs1137469145 & $1,14 \mathrm{E}-07$ & $170,926,834$ & NUBPL & $\begin{array}{l}1: 170866249- \\
171,111,362\end{array}$ & intronic (protein & coding) & \\
\hline
\end{tabular}

Noriker heterozygous for the associated allele), and SNP AX-104594172 (ECA17: 21,505,125), located within PHF11, showed a good, plausible, genotype distribution which included 33 Lipizzans, 6 Noriker, 9 Selle Francais, 4 Shagya-Arabians and 1 French Trotter, heterozygous for the vitiligo-like phenotype associated allele. The remaining three SNPs can be classified fair to good, as they indicate plausible associations, however exhibiting higher frequencies of the associated alleles among nongrey breeds.

Figure 3 illustrates the genotype distributions of the resulting five plausible associated SNPs. Together they explain $38.5 \%$ of phenotypic variance of vitiligo-like depigmentation grade. Although no perfect association can be seen in the histogram plots, plausible distributions are documented for AX-104837465 on ECA1 (located within NUBPL), AX-104594172 on ECA17 (located within PHF11; intergenic in a $+/-25 \mathrm{~kb}$ window of $R C B T B 1$ and $S E T D B 2$ ), and for AX-103697053 on ECA20 (located within PTP4A1). In total, we propose the genes NUBPL, PHF11, SETDB2, RCBTB1, PTP4A1, and at a weaker replication level the genes LITAFD, CARHSP1 and $O R 2 C 1$ as possible candidates for vitiligo-like depigmentation in grey horses.

\section{Discussion}

The prevalence of vitiligo-like depigmentation in this study was $21.7 \%$, and thus is in agreement with values cited in previous literature. 3.6 to $49.8 \%$ of grey P.R.E. horses [26], 26.0 to $67.0 \%$ of grey Kladrubian horses [25] and 39.9 to $50.0 \%$ of grey Lipizzan horses [24, 27] exhibit this depigmentation disorder. The SNP based heritability for vitiligo-like depigmentation was estimated as 0.31 , a value which also corresponds with results published in pedigree-data based studies $\left(\mathrm{h}^{2}\right.$ ranging from 0.35 to 0.64). While in the works of Curik et al. [24], Seltenhammer et al. [27] and Hofmanova et al. [25], all studied horses were of grey coat colour, the comprehensive data set of Sanchez-Guerrero et al. [26] allowed for the detection of vitiligo-like depigmentation in 0.8 to $3.5 \%$ 6392 non-grey horses. As a result, the prevalence of this depigmentation disorder in non-grey horses can be compared to human populations where the autoimmune disease vitiligo was observed in 0.5 to $2.0 \%$ of the population [1]. In addition to the higher incidence of vitiligo-like depigmentation, grey horses carrying the STX17 mutation also exhibit a higher incidence of melanoma, which ranges from 46.1 to $50.0 \%$ in grey Lipizzans [24, 27], from 12.5 to $16.0 \%$ in grey Kladrub horses [25], and from 1.5 
Table 4 Distribution of SNP genotypes from eleven significantly associated SNPs with gene annotation within the breeds AngloArabian, Shagya-Arabian, Purebred Arabian, Partbred Arabian, Exmoor Pony, Selle Francais, Lipizzan, French Trotter, and Noriker (NA = missing genotype)

\begin{tabular}{|c|c|c|c|c|c|c|c|c|c|c|c|}
\hline & & $\begin{array}{l}\text { Anglo } \\
\text { Arabian }\end{array}$ & $\begin{array}{l}\text { Shagya } \\
\text { Arabian }\end{array}$ & $\begin{array}{l}\text { Purebred } \\
\text { Arabian }\end{array}$ & $\begin{array}{l}\text { Partbred } \\
\text { Arabian }\end{array}$ & Exmoor Pony & Selle Francais & Lipizzan & French trotter & Noriker & Sum \\
\hline \multirow[t]{5}{*}{ ECA1 } & \multicolumn{11}{|c|}{ AX-104837465 } \\
\hline & 0 & 7 & 32 & 155 & 21 & 273 & 295 & 315 & 156 & 171 & 1425 \\
\hline & 1 & 0 & 0 & 0 & 0 & 0 & 0 & 46 & 0 & 2 & 48 \\
\hline & 2 & 0 & 0 & 0 & 0 & 0 & 0 & 4 & 0 & 0 & 4 \\
\hline & NA & 0 & 0 & 0 & 0 & 0 & 0 & 12 & 0 & 1 & 13 \\
\hline \multirow[t]{5}{*}{ ECA5 } & \multicolumn{11}{|c|}{ AX-104234663 } \\
\hline & 0 & 7 & 32 & 155 & 21 & 262 & 221 & 344 & 155 & 170 & 1367 \\
\hline & 1 & 0 & 0 & 0 & 0 & 9 & 72 & 24 & 1 & 3 & 109 \\
\hline & 2 & 0 & 0 & 0 & 0 & 1 & 2 & 0 & 0 & 0 & 3 \\
\hline & NA & 0 & 0 & 0 & 0 & 1 & 0 & 9 & 0 & 1 & 11 \\
\hline \multirow[t]{5}{*}{ ECA6 } & \multicolumn{11}{|c|}{ AX-104673609 } \\
\hline & 0 & 6 & 32 & 152 & 20 & 61 & 241 & 243 & 126 & 173 & 1054 \\
\hline & 1 & 1 & 0 & 3 & 1 & 141 & 51 & 102 & 28 & 1 & 328 \\
\hline & 2 & 0 & 0 & 0 & 0 & 71 & 3 & 23 & 1 & 0 & 98 \\
\hline & NA & 0 & 0 & 0 & 0 & 0 & 0 & 9 & 1 & 0 & 10 \\
\hline \multirow[t]{5}{*}{ ECA9 } & \multicolumn{11}{|c|}{ AX-104336590 } \\
\hline & 0 & 6 & 32 & 155 & 21 & 214 & 36 & 338 & 48 & 169 & 1019 \\
\hline & 1 & 0 & 0 & 0 & 0 & 30 & 109 & 30 & 61 & 4 & 234 \\
\hline & 2 & 0 & 0 & 0 & 0 & 0 & 77 & 0 & 15 & 1 & 93 \\
\hline & NA & 1 & 0 & 0 & 0 & 29 & 73 & 9 & 32 & 0 & 144 \\
\hline \multirow[t]{19}{*}{ ECA13 } & \multicolumn{11}{|c|}{ AX-104150856 } \\
\hline & 0 & 7 & 16 & 126 & 18 & 265 & 287 & 361 & 155 & 174 & 1409 \\
\hline & 1 & 0 & 14 & 28 & 3 & 1 & 7 & 15 & 0 & 0 & 68 \\
\hline & 2 & 0 & 1 & 1 & 0 & 0 & 0 & 0 & 0 & 0 & 2 \\
\hline & NA & 0 & 1 & 0 & 0 & 7 & 1 & 1 & 1 & 0 & 11 \\
\hline & \multicolumn{11}{|c|}{ AX-104939678 } \\
\hline & 0 & 7 & 27 & 130 & 19 & 273 & 295 & 356 & 156 & 174 & 1437 \\
\hline & 1 & 0 & 5 & 25 & 2 & 0 & 0 & 21 & 0 & 0 & 53 \\
\hline & 2 & 0 & 0 & 0 & 0 & 0 & 0 & 0 & 0 & 0 & 0 \\
\hline & \multicolumn{11}{|c|}{ AX-104387837 } \\
\hline & 0 & 7 & 25 & 104 & 17 & 262 & 254 & 353 & 113 & 171 & 1306 \\
\hline & 1 & 0 & 7 & 47 & 3 & 11 & 41 & 23 & 37 & 3 & 172 \\
\hline & 2 & 0 & 0 & 4 & 1 & 0 & 0 & 0 & 6 & 0 & 11 \\
\hline & NA & 0 & 0 & 0 & 0 & 0 & 0 & 1 & 0 & 0 & 1 \\
\hline & \multicolumn{11}{|c|}{ AX-104370576 } \\
\hline & 0 & 7 & 25 & 104 & 15 & 261 & 260 & 337 & 79 & 165 & 1253 \\
\hline & 1 & 0 & 7 & 47 & 4 & 11 & 31 & 33 & 57 & 5 & 195 \\
\hline & 2 & 0 & 0 & 4 & 1 & 0 & 1 & 0 & 20 & 0 & 26 \\
\hline & NA & 0 & 0 & 0 & 1 & 1 & 3 & 7 & 0 & 4 & 16 \\
\hline \multirow[t]{5}{*}{ ECA17 } & \multicolumn{11}{|c|}{ AX-104594172 } \\
\hline & 0 & 7 & 28 & 155 & 21 & 273 & 286 & 333 & 155 & 168 & 1426 \\
\hline & 1 & 0 & 4 & 0 & 0 & 0 & 9 & 33 & 1 & 6 & 53 \\
\hline & 2 & 0 & 0 & 0 & 0 & 0 & 0 & 0 & 0 & 0 & 0 \\
\hline & NA & 0 & 0 & 0 & 0 & 0 & 0 & 11 & 0 & 0 & 11 \\
\hline
\end{tabular}


Table 4 (continued)

\begin{tabular}{|c|c|c|c|c|c|c|c|c|c|c|c|}
\hline & & $\begin{array}{l}\text { Anglo } \\
\text { Arabian }\end{array}$ & $\begin{array}{l}\text { Shagya } \\
\text { Arabian }\end{array}$ & $\begin{array}{l}\text { Purebred } \\
\text { Arabian }\end{array}$ & $\begin{array}{l}\text { Partbred } \\
\text { Arabian }\end{array}$ & Exmoor Pony & Selle Francais & Lipizzan & French trotter & Noriker & Sum \\
\hline \multirow[t]{11}{*}{ ECA20 } & \multicolumn{11}{|c|}{ AX-103697053 } \\
\hline & 0 & 7 & 27 & 119 & 19 & 272 & 280 & 357 & 156 & 165 & 1402 \\
\hline & 1 & 0 & 5 & 35 & 2 & 1 & 14 & 12 & 0 & 2 & 71 \\
\hline & 2 & 0 & 0 & 1 & 0 & 0 & 1 & 4 & 0 & 0 & 6 \\
\hline & NA & 0 & 0 & 0 & 0 & 0 & 0 & 4 & 0 & 7 & 11 \\
\hline & \multicolumn{11}{|c|}{ AX-103235989 } \\
\hline & 0 & 5 & 32 & 61 & 12 & 226 & 234 & 233 & 77 & 166 & 1046 \\
\hline & 1 & 0 & 0 & 66 & 4 & 47 & 39 & 103 & 62 & 4 & 325 \\
\hline & 2 & 1 & 0 & 11 & 3 & 0 & 2 & 32 & 13 & 1 & 63 \\
\hline & NA & 1 & 0 & 17 & 2 & 0 & 20 & 9 & 4 & 3 & 56 \\
\hline & Sum & 7 & 32 & 155 & 21 & 273 & 295 & 377 & 156 & 174 & 1490 \\
\hline
\end{tabular}

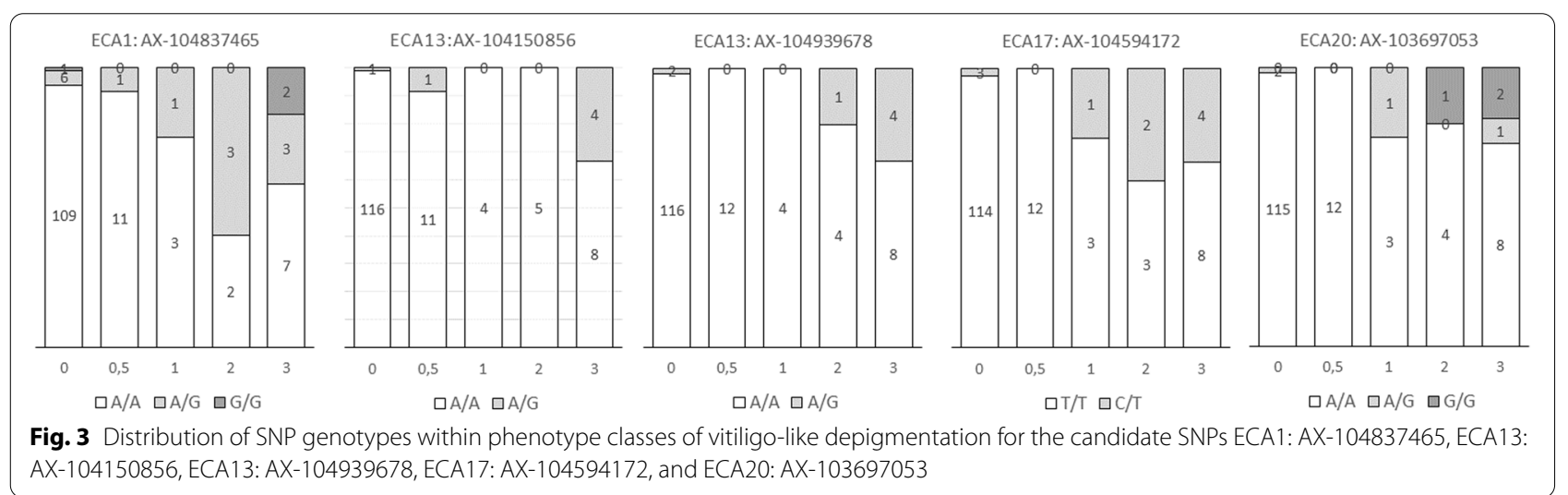

to $4.7 \%$ in grey P.R.E. horses [26]. In non-grey horses, Sanchez-Guerrera et al. [26] found a markedly lower melanoma incidence ranging from 0.7 to $0.9 \%$. Clinical studies in humans have shown an up to threefold reduced probability of vitiligo patients developing melanoma [28, 29]. Furthermore, several vitiligo susceptibility genes in humans, particularly those expressed in melanocytes, have been detected to be involved in susceptibility to malignant melanoma, but with opposite effects [30]. This inverse relationship led to the suggestion that vitiligo may represent a process of immune surveillance against malignant melanoma [1, 31]. A similar relationship has been reported in Sinclaire miniature swine, where certain breeding lines were selected for a high melanoma incidence [32]. In this animal model up to $85 \%$ of individuals develop melanoma, from which $90 \%$ resolve spontaneously followed by a vitiligo-like depigmentation of skin and hair (destruction of melanocytes) in the tumor location [33]. Collectively, these findings in vitiligo research correspond with reported prevalence and negative genetic correlations ( $\mathrm{r}$ from -0.34 to -0.09 [24, 26];) of vitiligo-like depigmentation and melanoma in horses.

Although early genetic segregation studies aimed to document the Mendelian modes of inheritance of human vitiligo, it rapidly became evident that this skin disorder represents a complex, multifactorial disease [31]. Currently, up to 322 genes related to vitiligo in humans have been addressed by 202 scientific articles, all of them incorporated in the VitiVar database [11] (www. http:// vitivar.igib.res.in). A common criterion for complex disorders is a polygenetic background including multiple loci with minor effects - making it difficult to derive stable concordance across populations in replication or verification studies. In this GWAS study on vitiligo-like depigmentation in Lipizzan horses, we were able to identify a total of eleven SNPs within or next to 16 annotated genes. Considering the previously discussed differences in vitiligo prevalence between horse breeds of grey and 
breeds of non-grey coat colour, we examined which of the eleven annotated SNPs resulted in meaningful genotype distributions in breeds (a) selected for grey coat colour, (b) where grey coat colour occurs at low to medium level, and (c) where the grey associated STX17 mutation is not segregating. This replication analysis resulted in five SNPs which led us to 9 different genes NUBPL, PHF11, SETDB2, RCBTB1, PTP4A1, LITAFD, CARHSP1 and $O R 2 C 1$.

Nucleotide binding protein-like (NUBPL), located on ECA1, is required for the assembly of human mitochondrial complex I, which contains 45 evolutionally conserved mitochondrial and nuclear encoded subunits. In addition to its central role for the mitochondrial respiratory chain, overexpression of NUBPL has been documented in melanoma and colorectal cancer tissue $[34,35]$. Although the effect of this gene on melanoma is still unclear, Wang et al. [35] characterized NUBPL as a metastasis-related gene as they were able to show that the overexpression of NUBPL in colorectal cancer tissue was positively correlated with lymph node metastasis and advanced staging of this form of cancer. The authors found that NUBPL induces epithelial-mesenchymal transition through the activation of ERK signaling pathway, a pathway which promotes tumor metastasis. Uncontrolled growth is a necessary step for the development of all cancers and activating mutations of ERK pathway were also shown to be essential for melanoma development and progression [36]. However, the antagonistic pathogenesis of vitiligo in relation to cancer specific enhanced cell motility and/or metastasis on typical melanoma predilection sites (eyes, muzzle, perianal region) may underline a plausible involvement of NUBPL into the genetics of vitiligo-like depigmentation in horses.

The significant SNP on ECA17 was assigned to three different genes: PHF11, SETDB2, RCBTB1. Plant homeodomain zinc finger protein 11 (PHF11) and its neighboring gene SET domain bifurcated histone lysine methyltransferase 2 (SETDB2), are both expressed in cells of the innate immune system and are involved in chromatin remodeling or transcriptional regulation. Several studies associated polymorphisms of these genes with increased serum IgE levels and asthma, eczema, and atopic dermatitis in humans $[37,38]$. In more recent studies, SETDB2 has been linked to epigenetic concepts [39]. The histone modifier SETDB2 was found to modulate adaptative resistance mechanisms in tumor development and in macrophage plasticity in inflammatory processes by regulating genomic stability and/or H3K9me3-mediated silencing of gene transcription $[39,40]$. Due to their involvement in immune reactions, macrophagy, metastasis promotion, and adaptive resistance in melanoma [39], PHF11 and SETDB2 fit in the classification categories of vitiligo related genes proposed by Shen et al. [2] and Kundu et al. [12]. In close proximity to PHF11 was the gene $R C B T B 1$, which is located within a $25 \mathrm{~kb}$ window to the associated SNP on ECA17. Chronic lymphocytic leukemia deletion gene 7 (RCBTB1, also called Clld7) has been described as a general candidate tumor suppressor [41]. Zhou and Münger [42] investigated biological functions of $R C B T B 1$ in osteosarcoma cell lines and found that this protein is responsible for inhibited cell growth and decreased cell viability. The same authors detected an indication for activation of the DNA damage/repair pathway, as reduction of Clld7 in epithelial cells resulted in resistance to apoptosis.

Another gene that was pinpointed by GWAS and replication analysis was PTP4A1, located at ECA20. Protein tyrosine phosphatase type IVA 1 belongs to a group of three prenylated PTPs (PTP4A1/2/3), which support growth and migration of tumor cells [43]. Sacchetti et al. [44] were able to show that PTP4A1 was highly expressed in fibroblasts of patients with the autoimmune disease systemic sclerosis. The tyrosine phosphatase PTP4A1 promotes transforming growth factor $\beta$ (TGF $\beta$ ) signaling in human fibroblasts through enhancement of ERK activity. A knockdown of PTP4A1 results in reduced ERK activation and correlates with reduced activity of the protooncogene SRC [44].

The genes LITAFD, CARHSP1 and OR2C1, all located on ECA13, exhibited less specific replication across breeds and cases in GWAS. SNP AX-104150856 is located in a $+/-25 \mathrm{~kb}$ window between the genes LITAFD and CARHSP1. Calcium-regulated heat-stable protein 1 (CARHSP1) is reported to act as a tumor necrosis factor alpha (TNF- $\alpha$ ) stability enhancer. As TNF- $\alpha$ is required for the control of infection and the subsequent immune response, it plays a central role for the host response to infection and injury [45]. LITAFD (LITAF domain containing) belongs to the CDIP1/LITAF family. Similar to CARHSP1, the gene LITAF also encodes a transcription factor regulating the gene expression of the inflammatory mediator TNF- $\alpha$ [46]. Considered as tumor suppressor in several cancer types, LITAF was also shown to be involved in immune response and autophagy [47]. For OR2C1 no specific biological roles has been reported yet.

Overall, GWAS analysis of vitiligo-like depigmentation in the current study pinpointed seven genes with known biological role in the following fields: (a) immune response - PHF11, SETDB2, CARHSP1, LITAF; (b) tumor suppression - RCBTB1, LITAF; and (c) enhanced proliferation in metastasis - NUBPL, PTP4A1. While cancer related genes (b) and (c) may reflect the antagonistic relation between vitiligo and melanoma proposed by Spritz [30], the highlighted genes related to immune response 
represent classical features of the immune regulatory theory of vitiligo pathogenesis proposed by Shen et al. [2].

\section{Conclusions}

Given the complex nature of the skin disorder vitiligo, the seven highlighted genes by GWAS of vitiligo-like depigmentation in grey horses need further verification by expression studies and replication studies across breeds. The current study indicates a relationship between this depigmentation phenotype and melanoma in grey horses and represents a research question that needs further investigation.

\section{Material and methods Sample cohort}

In the year 2020, 152 Lipizzan horses (60 mares and 92 stallions) from the Austrian federal stud farm Piber and the Spanish Riding School Vienna were phenotyped for vitiligo-like depigmentation by visual inspection according to the protocol of Curik et al. [24]. The following grades of vitiligo-like depigmentation were recorded: grade $0=$ no depigmentation; grade $0.5=$ beginning of non-segmental depigmentation via few small spots in the muzzle, perianal region; grade $1=$ clearly visible non-segmental depigmentation in muzzle and perianal region; grade $2=$ extended distribution of non-segmental depigmentation in face and eventually a few small segmented depigmentation areas, grade $3=$ prevalence of extended sharp segmented depigmentation areas around muzzle, eyes and face (Fig. 4). The age of studied horses ranged from 4 to 34 years, with a mean age of 15.06 years (s.d. +7.05 ), whereas 140 horses of the sample were older than 6 years, thus taking the etiology of this skin disorder into account $[24,25]$. For all phenotyped horses, genotype data was available from previous studies [48-50] and this study was performed with the permission by the owner (Spanische Hofreitschule und Lipizzanergestüt Piber GöR). Blood/hair samples from these horses were collected under appropriate terms regarding ethical approvements (Commission for Ethics and Animal Welfare, University of Veterinary Medicine, Vienna, protocol number: ETK-06/05/2015, in accordance with GSP guidelines and national legislation) and were genotyped using the Axiom Equine Genotyping array (MNEc670k, Affymetrix, Inc., Santa Clara, CA, USA [51];).

\section{SNP quality control}

As vitiligo-like depigmentation in grey horses develops with age $[24,25]$, we can assume that in a certain number of young horses, this depigmentation disorder may not yet be visible. In order to overcome this problem, we included 104 solid coloured horses from the Noriker breed without vitiligo-like characteristics as a control group. Quality control (QC) of the sample cohort consisting of 152 Lipizzan and 104 Noriker horses was performed using the software PLINK 1.07 [52]. SNPs located on sex chromosomes (X: 28,017 SNPs and Y: 1 SNP) and 30.864 SNPs without chromosomal assignment were excluded from further analysis. We further applied a filter for genotyping call rate for individuals of min. 95\% and retained SNPs with a minor allele frequency larger than $1 \%$, which resulted in 376,219 SNPs and 255 horses (104 Noriker, 151 Lipizzans) that passed QC.

\section{Determination of MC1R, ASIP and STX17 genotypes and statistical analysis}

In order to test the putative effects of the coat colour genes ASIP, MC1R and STX17 on the vitiligo phenotype data, we used the $670 \mathrm{k}$ SNP data to derive the genotypes of respective loci. For $M C 1 R$ the causative point mutation is directly contained by the SNP AX-104805525 (ECA3:36,259,552) in the Affymetrix ${ }^{\circledR}$ Axiom Equine HD Array. From previous studies [49] the ASIP genotype was known for 118 horses. In a recent study, Corbin et al. [53] used the SNP AX-103951024 (ECA22: 24,877,990) to tag the ASIP deletion [54]. However, the respective SNP genotypes of the 152 analyzed Lipizzans were monomorphic, thus we correlated five SNPs (AX-103929593,

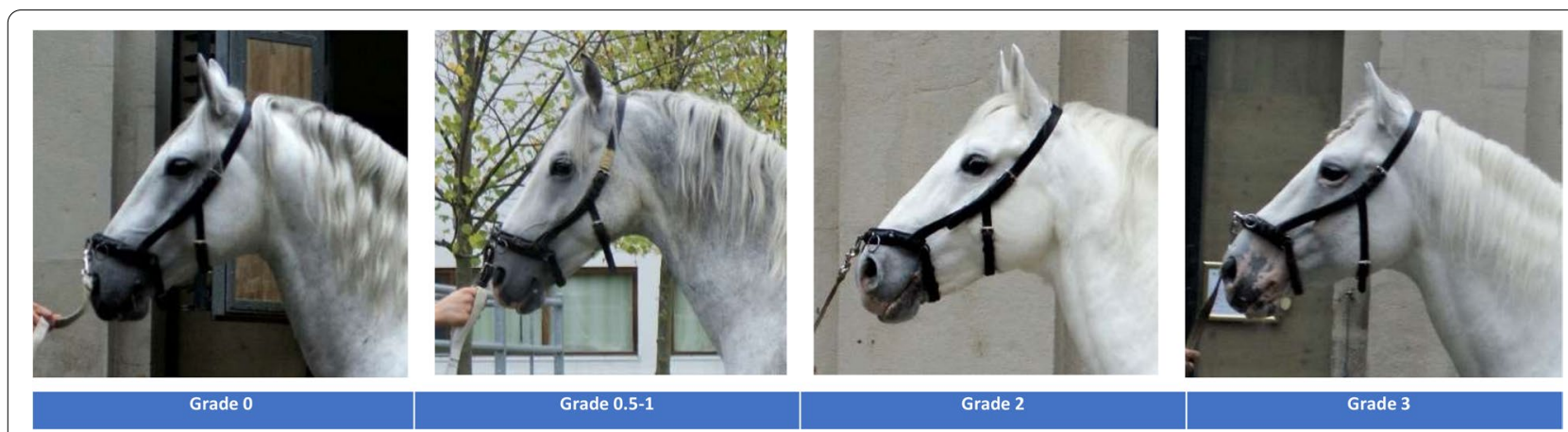

Fig. 4 Phenotypic classification of vitiligo-like depigmentation 
ECA22:25,147,724; AX-103057353, ECA22:25,148,247; AX-102968633, ECA22:25,161,695; AX-104134604, ECA22:25,175,554; AX-103402623, ECA22:25,176,678; AX-103271875, ECA22:25,187,112) around the ASIP locus (ECA22:25,165.083-25,173,072) with the known ASIP genotypes of 118 Lipizzan horses derived from KASP (competitive allele specific PCR) analysis according to Rieder et al. [54]. The highest correlation $(r=0.97)$ was found for the SNP AX-102968633, whereas the correlation of the other four SNPs ranged between 0 and 0.21 . Four observations from 118 did not match the KASP results, implying an error rate of 1.15 horses for the SNP derived genotype of 34 horses missing the ASIP genotype information. The STX17 genotype was known for 130 Lipizzan horses from the study of Grilz-Seger et al. [49] by genotyping the causative $4.6 \mathrm{~kb}$ duplication in intron 6 of syntaxin 17 following the method of Kavar et al. [55]. In the work of Grilz-Seger et al. [38] the authors demonstrated that the STX17 locus was surrounded by a selection signature, a $350 \mathrm{~kb} \mathrm{ROH}$ (run of homozygosity) haplotype, that was shared by $70 \%$ homozygous grey horses. In order to derive the 22 missing STX17 genotypes, we performed a $\mathrm{ROH}$ analysis for all 152 horses in our sample using the software PLINK 1.07 [52] and the following setting: minimal SNP density of one SNP per $50 \mathrm{~kb}$, maximal distance between two homozygous segments of $100 \mathrm{~kb}$, minimum length of homozygous segment of $80 \mathrm{~kb}$ and/or 20 consecutive SNPs per segment, one heterozygote and one missing SNP were allowed. The resulting ROHs were assigned to STX17 genotypes as follows: (a) coloured Lipizzans - STX17 genotype $g / g$; (b) grey Lipizzans with $\mathrm{ROH}$ haplotype around STX17 - genotype G/G; (c) grey Lipizzans without $\mathrm{ROH}$ around STX17 - genotype G/g. Resulting ROH genotypes of 130 horses were correlated with known STX17 genotypes from fragment genotyping analysis, revealing a correlation of 0.89 (8 from 130 genotypes were wrongly assigned, implying that 1.3 horses out of 22 horses with unknown STX17 genotypes can be wrongly estimated.

To test the putative influence of the factors ASIP, $M C 1 R$ and STX17 genotype, and age class on vitiligo-like depigmentation grade, we applied the following generalized linear model (GLM):

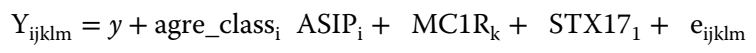

where:

$\mathrm{Y}_{\mathrm{ijk} \mathrm{lm}}=$ observations.

$y=$ mean.

age_class ${ }_{\mathrm{i}}=$ age effect in age classes $(6: 4$ to 6 years, 8: 7 to 8 years; 10 : 9 to 10 years; 12 : 11 to 12 years; $14: 13$ to 14 years; 18 : 15 to 18 years; $22: 19$ to 22 years; $30: 23$ to 34 years).
$\mathrm{ASIP}_{\mathrm{j}}=$ effect of ASIP genotype $(A / A, A / a, a / a)$.

$M C 1 \mathrm{R}_{\mathrm{k}}=$ effect of MC1R genotype $(E / E, E / e, e / e)$.

$\mathrm{STX}_{17}=$ effect of STX17 genotype $(G / G, G / g, g / g)$.

$\mathrm{e}_{\mathrm{ijklm}}=$ residual error.

Statistical analyses and graphical representations were performed using the software package SAS [56], SNP data management was done with PLINK 1.07 [52].

\section{GWAS analysis and replication study}

GWAS analysis and heritability estimation for vitiligolike depigmentation grade were performed using the software GCTA v. 1.91.6 [57]. The GWAS was carried out using the mixed linear model association $(-$ mlma $)$ method, thus taking genetic structure and individual relationship within the data into account:

$$
Y_{i j}=b_{j} S N P_{i j}+g_{i}+e \sim N\left(0, I \sigma_{e^{2}}\right)
$$

where $y_{i j}$ was the phenotype of the ${ }_{i}$ th individual, $b_{j}$ was the allele substitution effect of the ${ }_{j}$ th SNP marker, $\mathrm{SNP}_{i j}$ was the genotype of the ${ }_{i}$ th animal for the ${ }_{j}$ th SNP, $g_{i}$ was the random polygenic effect of the ${ }_{i}$ th individual, and $e_{i j}$ was the random residual effect for the ${ }_{i}$ th individual and jth SNP. The polygenic effects (g) followed a normal distribution $\mathrm{g} \sim \mathrm{N}\left(0, \mathrm{G \sigma}_{\mathrm{g}}{ }^{2}\right)$, where $\mathrm{G}$ was the genomic relationship matrix (calculated as described by Yang et al. [57], and the residuals followed a normal distribution $\mathrm{e} \sim \mathrm{N}\left(0, \mathrm{I}_{\mathrm{e}}^{2}\right)$. The STX17 genotype was included in the GWAS as a covariate. Heritability for vitiligo-like depigmentation grade was estimated by the -reml command in the GCTA software [57].

Adjustment for genome-wide multiple testing of association statistics was carried out according to the Bonferroni method, which adjusts the $p$ value threshold from $p=0.05$ to $\mathrm{p}=0.05 / \mathrm{k}$, where $\mathrm{k}$ is the number of SNPs $(376,219)$ in the GWAS, thus reaching a threshold of $p<1.33 \mathrm{e}-7$. Manhattan plots and quantile-quantile plots were generated in $\mathrm{R}$ (www.r-project.com) using the package qqman.

For the identification of potential candidate genes for equine vitiligo-like depigmentation, we applied a two-step procedure, which is described as follows: step 1 - gene annotation: We screened the genome in $\mathrm{a}+/-25 \mathrm{~kb}$ window frame surrounding each significantly associated SNP in the Ensembl genome database EquCab3.0 (www.ensembl.org). In the event that a SNP was located between two genes within the defined window frame, both genes were selected; step 2 - replication study of significant SNPs with gene annotation. We screened eight horse breeds for genotype distribution of the identified significant SNPs with gene annotation. With this replication study we aimed to determine which of the SNPs were segregating ubiquitously or specific in populations with: (a) higher STX17 G-allele 
frequency (Lipizzan, Arabian populations); (b) where STX17 G-allele is not segregating (Exmoor Pony and Noriker); and (c) where STX17 G-allele can occur at low to moderate frequency (Selle Francais and French Trotter). The HD $670 \mathrm{k}$ SNP genotype data set was comprised of 1490 samples from 377 Lipizzan horses, 174 Noriker horses, 32 Shagya Arabians, 155 Purebred Arabians, 21 Partbred Arabians, 7 Anglo-Arabians, 273 Exmoor Ponies, 295 Selle Francais, and 156 French Trotters. This data had already been published in GrilzSeger et al. [50] and was used for this replication study by consent of the authors.

\section{Authors' contributions}

G.Grilz-Seger: research idea, conceptualization, funding acquisition, scientific support, phenotyping; T.Druml: formal analyses, phenotyping, writing of the manuscript; G.Brem: scientific and financial support; G.Lindgren: data contribution, scientific support; B.Velie: data contribution, scientific support; A.Ricard: data contribution, scientific support; M.Horna: data contribution, scientific support. The author(s) read and approved the final manuscript.

\section{Funding}

This work was financially supported by the Austrian Federal Ministry for Sustainability and Tourism (BMNT), Contract numbers 101332 and 101483. Data collection and genotyping of the Exmoor Pony received funding from the European Union's Seventh Framework Program managed by REA-Research Executive Agency; http://ec.europa.eu/research/rea (FP7/2007e2013) under grant agreement no. 606142 and The Exmoor Pony Society in the UK. Open Access funding for this article was provided by the University of Veterinary Medicine Vienna (Vetmeduni Vienna)

\section{Availability of data and materials}

The primary data of this study are owned by different research groups. Primary data of the breeds Lipizzan, Noriker, Shagya Arabian are available from project consortium FFG project number 843464, Veterinary University Vienna, Xenogenetik, five European state stud farms and the Austrian Horse breeders Association, but restrictions apply to the availability of these data, which were used under license for the current study, and so are not publicly available. Data are however available from the authors upon reasonable request and with permission of project consortium, FFG project number 843464 , Veterinary University Vienna, Xenogenetik and partners. Genotype data for the Exmoor Pony breed can be provided by contacting authors Lindgren/ Velie or for a larger data set via the following reference: Velie, B.D.; Shrestha, M.; François, L.; Schurink, A.; Tesfayonas, Y.G.; Stinckens, A.; Blott, S.; Ducro, B.J.; Mikko, S.; Thomas, R.; Swinburne, J.E.; Sundqvist, M.; Eriksson, S.; Buys, N.; Lindgren, $G$. Using an inbred horse breed in a high density genome-wide scan for genetic risk factors of insect bite hypersensitivity (IBH). PLoS One. 2016, 11, e0152966.

\section{Declarations}

Ethics approval and consent to participate

Samples were collected under appropriate terms regarding ethical approvements (Commission for Ethics and Animal Welfare, University of Veterinary Medicine, Vienna, protocol number: ETK-06/05/2015) in accordance with GSP guidelines and national legislation.

\section{Consent for publication}

All authors read and approved the final version of the manuscript.

\section{Competing interests}

The authors declare that there are no competing interests.

\section{Author details}

${ }^{1}$ Institute of Animal Breeding and Genetics, University of Veterinary sciences Vienna, Veterinärplatz 1, A-1210 Vienna, Austria. ${ }^{2}$ Equine Genetics \& Genomics Group, School of Life \& Environmental Sciences, University of Sydney, Sydney, Australia. ${ }^{3}$ Department of Animal Breeding and Genetics, Swedish University of Agricultural Sciences Uppsala, Uppsala, Sweden. ${ }^{4}$ Livestock Genetics, Department of Biosystems, KU Leuven, Leuven, Belgium. ${ }^{5}$ Department of Animal Husbandry, Slovak University of Agriculture in Nitra, Nitra, Slovakia. ${ }^{6} \mathrm{GABI}$, INRAE, AgroParisTech, Université Paris-Saclay, 78350 Jouy-en-Josas, France. ${ }^{7}$ Pôle Développement Innovation Recherche, IFCE, 61310 Gouffern en Auge, France.

Received: 30 July 2021 Accepted: 3 October 2021

Published online: 25 October 2021

References

1. Kingsley IE, Harris JE. Animal models of vitiligo: matching the model to the question. Dermatol Sin. 2014;32:240-7.

2. Shen C, Gao J, Sheng Y, Dou J, Zhou F, Zheng X, et al. Genetic susceptibility to vitiligo: GWAS approaches for identifying vitiligo susceptibility genes and loci. Front Genet. 2016. https://doi.org/10.3389/fgene.2016.00003.

3. Puri N, Mojamdar M, Ramaiah A. In vitro growth characteristics of melanocytes obtained from adult normal and vitiligo subjects. J Invest Dermatol. 1987:88:434-8.

4. Jimbow K, Chen H, Park JS, Thomas PD. Increased sensitivity of melanocytes to oxidative stress and abnormal expression of tyrosinase-related protein in vitiligo. Brit J Dermatol. 2001;144:55-65.

5. Kroll TM, Bommiasamy H, Boissy RE, Hernandez C, Nickoloff BJ, Mestril R. Caroline Le Poole I. 4-Tertiary butyl phenol exposure sensitizes human melanocytes to dendritic cell-mediated killing: relevance to vitiligo. J Invest Dermatol. 2005:124:798-806.

6. Yu R, Huang Y, Zhang X, Zhou Y. Potential role of neurogenic inflammatory factors in the pathogenesis of vitiligo. J Cutan Med Surg. 2012;16:230-44.

7. Ogg GS, Rod Dunbar P, Romero P, Chen JL, Cerundolo V. High frequency of skin-homing melanocyte-specific cytotoxic T lymphocytes in autoimmune vitiligo. J Exper Med. 1998;188:1203-8.

8. Lang KS, Caroli CC, Muhm A, Wernet D, Moris A, Schittek B, et al. HLA-A2 restricted, melanocyte-specific CD8(+) T lymphocytes detected in vitiligo patients are related to disease activity and are predominantly directed against MelanA/MART1. J Invest Dermatol. 2001;116:891-7.

9. Rodrigues M, Ezzedine K, Hamzavi I, Pandya AG, Harris JE. Vitiligo working group. New discoveries in the pathogenesis and classification of vitiligo. J Amer Acad Dermatol. 2017:77:1-13.

10. Jin Y, Andersen G, Yorgov D, Ferrara TM, Ben S, Brownson KM, et al. Genome-wide association studies of autoimmune vitiligo identify 23 new risk loci and highlight key pathways and regulatory variants. Nat Genet. 2016;48:1418-24.

11. Gupta I, Narang A, Singh P, Manchanda V, Khanna S, Indian genome variation consortium, et al. VitiVar: A locus specific database of vitiligo associated genes and variations. Gene X. 2019:3:100018.

12. Kundu RV, Mhlaba JM, Rangel SM, Le Poole IC. The convergence theory for vitiligo: a reappraisal. Exper Dermatol. 2019:28:647-55.

13. Lei Z, Yu S, Ding Y, Liang J, Halifu Y, Xiang F, et al. Identification of key genes and pathways involved in vitiligo development based on integrated analysis. Medicine. 2020;99:e21297.

14. Tham HL, Linder KE, Olivry T. Autoimmune diseases affecting skin melanocytes in dogs, cats and horses: vitiligo and the uveodermatological syndrome: a comprehensive review. BMC Vet Res. 2019;15:251.

15. Naughton GK, Mahaffey M, Bystryn JC. Antibodies to surface antigens of pigmented cells in animals with vitiligo. Proc Soc Exp Biol Med. 1986:181:423-6.

16. Meijer WCP. Dermatological diagnosis in horse and cattle judging. Vet Rec. 1965;77:1046-7.

17. Meijer WCP. Vitiligo in the horse: the so-called 'neigeuses'. Neth J Vet Sci. 1961;86:1021-6. 
18. Meijer WCP. Vitiligo in horses and cattle. Neth J Vet Sci. 1962;87:411-7.

19. McLean LM, Jones WE. Depigmentation - copper supplement therapy a case report. J Equine Vet Sci. 1983:3:208-10.

20. Montes LF, Wilborn WH, Hyde BM, Vaughan JT, Bennett JS. Vitiligo in a quarter horse filly: Clinicopathologic, ultrastructural and nutritional study. J Equine Vet Sci. 2008;28:171-5.

21. Mozos E, Novales M. sierra MA. Focal hypopigmentation in horses resembling Arabian fading syndrome. Equine Vet Educ 1991;3:122-125.

22. Scott DW, Miller WH. Pigmentary abnormalities. In: Scott DW, Miller WH, editors. Equine Dermatology. 2nd ed. Maryland Heights: Elsevier/ Saunders; 2011. p. 391-2.

23. Rosengren Pielberg G, Golovko A, Sundström E, Curik I, Lennartsson J, Seltenhammer $\mathrm{MH}$, et al. A cis-acting regulatory mutation causes premature hair graying and susceptibility to melanoma in the horse. Nat Genet. 2008;40:1004-9.

24. Curik I, Druml T, Seltenhammer M, Sundström E, Pielberg GR, Andersson $L$, et al. Complex inheritance of melanoma and pigmentation of coat and skin in Grey horses. PLoS Genet. 2013;9:e1003248.

25. Hofmanová B, Vostrý L, Majzlík I, Vostrá-Vydrová H. Characterization of greying, melanoma, and vitiligo quantitative inheritance in old Kladruber horses. Czech J Anim Sci. 2015;60:443-51.

26. Sánchez-Guerrero MJ, Solé M, Azor PJ, Sölkner J, Valera M. Genetic and environmental risk factors for vitiligo and melanoma in Pura Raza Español horses. Equine Vet J. 2019;51:606-11.

27. Seltenhammer MH, Simhofer H, Scherzer S, Zechner P, Curik I, Sölkner J, et al. Equine melanoma in a population of 296 grey Lipizzaner horses. Equine Vet J. 2003:35:153-7.

28. Teulings HE, Overkamp M, Ceylan E, Nieuweboer-Krobotova L, Bos JD, Nijsten T, et al. Decreased risk of melanoma and nonmelanoma skin cancer in patients with vitiligo: a survey among 1307 patients and their partners. Brit J Dermatol. 2013;168:162-71.

29. Paradisi A, Tabolli S, Didona B, Sobrino L, Russo N, Abeni D. Markedly reduced incidence of melanoma and nonmelanoma skin cancer in a nonconcurrent cohort of 10,040 patients with vitiligo. J Am Acad Dermatol. 2014;71:1110-6.

30. Spritz RA. The genetics of generalized vitiligo: autoimmune pathways and an inverse relationship with malignant melanoma. Genome Med. 2010;2:78.

31. Spritz RA, Andersen GH. Genetics of vitiligo. Dermatol Clin. 2017;35:245-55

32. Misfeldt ML, Grimm DR. Sinclaire miniature swine: an animal model of human melanoma. Vet Immunol Immunopathol. 1994;43:167-75.

33. Lentz KJ, Burns RP, Loeffler K, Feeney-Burns L, Berkelhammer J, Hook RR. Uveitis caused by cytotoxic immune response to cutaneous malignant melanoma in swine: destruction of uveal melanocytes during tumor regression. Invest Ophthalmol Vis Sci. 1983;24:1063-9.

34. Hoek KS. DNA microarray analyses of melanoma gene expression: a decade in the mines. Pigment Cell Res. 2007;20:466-84.

35. Wang $Y$, Wu N, Sun D, Sun H, Tong D, Liu D, et al. NUBPL, a novel metastasis-related gene, promotes colorectal carcinoma cell motility by inducing epithelial-mesenchymal transition. Cancer Sci. 2017;108:1169-76.

36. Savoia P, Fava P, Casoni F, Cremona O. Targeting the ERK signaling pathway in melanoma. Int J Mol Sci. 2019:20:1483.

37. Jang N, Stewart G, Jones G. Polymorphisms within the PHF11 gene at chromosome $13 \mathrm{q} 14$ are associated with childhood atopic dermatitis. Genes Immun. 2005;6:262-4.

38. Holt RJ, Vandiedonck C, Willis-Owen SA, Knight JC, Cookson WO, Moffatt MF, et al. A functional AT/G polymorphism in the $5^{\prime}$-untranslated region of SETDB2 in the IgE locus on human chromosome 13q14. Genes Immun. 2015;16:488.

39. Torrano J, Al Emran A, Hammerlindl H, Schaider $\mathrm{H}$. Emerging roles of H3K9me3, SETDB1 and SETDB2 in therapy-induced cellular reprogramming. Clin Epigenet. 2019;11:43.

40. Kimball AS, Davis FM, denDekker A, Joshi AD, Schaller MA, Bermick J et al. The histone methyltransferase Setdb2 modulates macrophage phenotype and uric acid production in diabetic wound repair. Immunity. 2019;51:258-71.

41. Mabuchi H, Fujii H, Calin G, et al. Cloning and characterization of CLLD6, CLLD7, and CLLD8, novel candidate genes for leukemogenesis at chromosome 13q14, a region commonly deleted in B-cell chronic lymphocytic leukemia. Cancer Res. 2001;61:2870-7.
42. Zhou X, Münger K. Clld7, a candidate tumor suppressor on chromosome $13 q 14$, regulates pathways of DNA damage/repair and apoptosis. Cancer Res. 2010;70:9434-43.

43. Bessette DC, Qiu D, Pallen CJ. PRL PTPs: mediators and markers of cancer progression. Cancer Metastasis Rev. 2008;27:231-52.

44. Sacchetti C, Bai Y, Stanford SM, Di Benedetto P, Cipriani P, Santelli E, et al. PTP4A1 promotes TGF $\beta$ signaling and fibrosis in systemic sclerosis. Nat Commun. 2017;8:1060.

45. Pfeiffer JR, McAvoy BL, Fecteau RE, Deleault KM, Brooks SA. CARHSP1 is required for effective tumor necrosis factor alpha mRNA stabilization and localizes to processing bodies and exosomes. Mol Cell Biol. 2011;31:277-86.

46. Takashiba S, Van Dyke TE, Shapira L, Amar S. Lipopolysaccharide-inducible and salicylate-sensitive nuclear factor(s) on human tumor necrosis factor alpha promoter. Infect Immun. 1995;63:1529-34.

47. Bertolo C, Roa S, Sagardoy A, Mena-Varas M, Robles EF, Martinez-Ferrandis Jl, et al. LITAF, a BCL6 target gene, regulates autophagy in mature B-cell lymphomas. Brit J Haematol. 2013;162:621-30.

48. Grilz-Seger G, Druml T, Neuditschko M, Dobretsberger M, Horna M, Brem G. High-resolution population structure and runs of homozygosity reveal the genetic architecture of complex traits in the Lipizzan horse. BMC Genomics. 2019;20:174.

49. Grilz-Seger G, Dobretsberger M, Brem G, Druml T. Untersuchungen zum Allelstatus einzelner Farbloci und Abzeichen beim Lipizzaner. Züchtungskunde. 2020;92:76-86.

50. Grilz-Seger G, Neuditschko M, Ricard A, Velie B, Lindgren G, Mesarič M, et al. Genome-wide homozygosity patterns and evidence for selection in a set of European and near eastern horse breeds. Genes. 2019;10:491.

51. Schaefer RJ, Schubert M, Bailey E, Bannasch DL, Barrey E, Bar-Gal GK, et al. Developing a 670k genotyping array to tag 2M SNPs across 24 horse breeds. BMC Genomics. 2017;18:565-83.

52. Purcell S, Neale B, Todd-Brown K, Thomas L, Ferreira MA, Bender D, et al. PLINK: a tool set for whole genome association and population-based linkage analyses. Am J Hum Genet. 2007;81:559-75.

53. Corbin LJ, Pope J, Sanson J, Antczak DF, Miller D, Sadeghi R, et al. An independent locus upstream of ASIP controls variation in the shade of the bay coat colour in horses. Genes. 2020;11:606.

54. Rieder S, Taourit S, Mariat D, Langlois B, Guérin G. Mutations in the agouti (ASIP), the extension (MC1R), and the brown (TYRP1) loci and their association to coat color phenotypes in horses (Equus caballus). Mam Genome. 2001;12:450-5.

55. Kavar T, Čeh E, Dovč P. A simplified PCR-based method for detection of gray coat color allele in horse. Mol Cell Probes. 2012;26:256-8.

56. SAS Institute. SAS university edition. 2021. Cary (NC): SAS institute, Inc

57. Yang J, Lee SH, Goddard ME, Visscher PM. GCTA: a tool for genome-wide complex trait analysis. Am J Hum Genet. 2011;88:76-82.

\section{Publisher's Note}

Springer Nature remains neutral with regard to jurisdictional claims in published maps and institutional affiliations.

Ready to submit your research? Choose BMC and benefit from:

- fast, convenient online submission

- thorough peer review by experienced researchers in your field

- rapid publication on acceptance

- support for research data, including large and complex data types

- gold Open Access which fosters wider collaboration and increased citations

- maximum visibility for your research: over $100 \mathrm{M}$ website views per year

At BMC, research is always in progress.

Learn more biomedcentral.com/submissions 